\title{
Análisis lingüístico-cultural del imaginario de los judíos a través los refranes ${ }^{1}$
}

\section{(Linguistic and cultural survey of the Jewish traditions in the light of their proverbs)}

\author{
LUCíA LUQUE NADAL \\ fe1lunal@uco.es \\ Universidad de Córdoba
}

Fecha de recepción: 12 de julio de 2012

Fecha de aceptación: 15 de octubre de 2012

Resumen: El presente trabajo expone la relación directa que existe entre los refranes sobre los judíos en español y el imaginario que sobre estos se ha creado a lo largo de los siglos en España. La relación entre el lenguaje y la ideología es tan estrecha que incluso un imaginario, basado más o menos en prejuicios, es capaz de resistir el avance del tiempo aun cuando el objeto de dichos prejuicios haya desaparecido de la sociedad y no tenga vigencia alguna en ella, como en el caso de los judíos en España o el caso de las expresiones antisemitas en la lengua polaca actual. Para establecer el imaginario sobre los judíos se han analizado y dividido los refranes que hacen alusión a los judíos en diversos apartados: apariencia física, carácter, religión, economía, relación con los cristianos, etc. Se ha concluido que el imaginario que se obtiene del análisis de los refranes sobre judíos ofrece una serie de estereotipos muy parecidos a los que existen en otras lenguas europeas. Finalmente y como se observa en el ejemplo del polaco, un imaginario pervive en la lengua siempre que pervivan las expresiones paremiológicas y fraseológicas que lo sustentan.

Palabras clave: Paremias. Fraseologismos. Ideología. Cultura. Prejuicios.

Abstract: This paper describes the direct relationship between Spanish proverbs about Jews and the imaginary that has been created upon these proverbs. The relationship between language and ideology is so strong that even an imaginary, more or less based on prejudices, is capable of resisting the passing of ages even when the object of prejudice has disappeared from society and have no effect whatsoever on it, as in the case of the Jews in Spain or the latest case of anti-Semitic expressions in the Polish language today. In order to build up the imaginary about Jews we have analized and divided the proverbs that refer to Jews in several sections: physical appearance, character, religion, economy, relations with Christians, and so on. It was concluded that the imaginary obtained from the analysis of the proverbs about Jews offers a picture

\footnotetext{
${ }^{1}$ Este trabajo se enmarca dentro de las investigaciones llevadas a cabo en el Proyecto de Investigación del MICINN titulado 'Implementación del Diccionario Lingüístico Cultural' FFI2010-18922 (2010-2013).
} 
very similar to that in other European languages. Finally, as shown in the example of Poland, an imaginary survives in a language as long as the paremiological and idiomatic expressions that sustain it exist in the language.

Key words: Proverbs. Idioms. Ideology. Culture. Prejudices.

\section{REFRANES, IDEOLOGía Y CULTURA}

Los refranes y fraseologismos de cualquier lengua están íntimamente conectados con la ideología dominante en un determinado país o en una determinada cultura. Según afirman, entre otros autores, Ferro Ruibal $\left(2005^{2}, 2008\right)$, Luque Durán (2005) y Pamies Bertrán (2005), el conjunto de fraseologismos y paremias conforman una suerte de 'radiografía' a través de la cual conocer el conjunto de valores que rigen una determinada cultura.

Es por ello que se deben estudiar fraseologismos y paremias no como unidades aisladas sino como unidades que conforman redes y conjuntos de imágenes que se repiten constantemente y las que, a la larga, construyen la opinión que los hablantes tienen sobre cualquier acontecimiento histórico, grupos social, virtudes y valores, etc. Es decir, los hablantes de una lengua plasman en el lenguaje sus creencias pero a la vez las expresiones que expresan dichas creencias sirven para reforzar día a día las mismas y también para transmitirlas en forma de ideas preconcebidas y en muchas ocasiones como prejuicios.

\section{EL RETRATO DE LOS JUDÍOS A TRAVÉS DE LOS REFRANES ESPAÑOLES}

Si analizamos los proverbios españoles podremos dibujar un retrato robot de un país y una época (como el citado trabajo de Xesus Ferro Ruibal para Galicia). Los refranes son un decálogo ingenuo de los sistemas de valores sobre la familia, los poderes públicos, el trabajo, la mujer, los hijos, las relaciones interpersonales con amigos, parientes, autoridades, miembros del clero, etc. Así por ejemplo, la abundancia de fraseologismos españoles relacionados con la iglesia refleja el importante papel que esta institución ha tenido durante muchos siglos en España. Lo mismo cabe decir de los fraseologismos que reflejan actividades específicas de España como por ejemplo el mundo de los toros.

En concreto en este trabajo queremos proponer un retrato robot de la imagen que se tenía en la España medieval a través del análisis pormenorizado de los refranes que de ellos existían. Una simple ojeada a

\footnotetext{
${ }^{2}$ Ferro Ruibal en su trabajo "La fraseología: espejo de la historia de un pueblo" desarrolla los temas que más importancia tienen para el pueblo gallego. Así, Ferro Ruibal cita la inmigración a América y a Castilla y también otros temas como el hambre, la pobreza, los niños expósitos, el Camino de Santiago y personajes típicamente gallegos como Xan de Outeiro
} 
los refranes sobre judíos que encontramos en García De Castro (2006), Correas (1627, 2000), Cejador y Frauca (2008), Sbarbi (1922, 1943), Carrasco y Andrés Suárez (1995), Combet (1971) y otros, nos muestra un panorama pormenorizado de la opinión que les merecían los judíos a los españoles de la Edad Media ${ }^{3}$. Estos refranes nos dibujan un retrato robot no solo de actividades, creencias, y relación con los cristianos que tenían los judíos sino de los juicios y prejuicios que los cristianos se habían formado de esta comunidad ${ }^{4}$.

Como suele suceder, el imaginario ${ }^{5}$, en términos de Castoriadis, parece ser más fuerte que la realidad y los acontecimientos históricos demostraron que la difícil relación de cristianos y judíos a lo largo de los siglos se basó en una incomprensión basada en una visión distorsionada de ellos que acabó provocando la expulsión de los judíos de España. Esta visión no solo afectaba a España ya que en otros países de Europa el imaginario de los judíos era muy parecido. Así por ejemplo, en Inglaterra donde los judíos permanecieron desde el siglo XI hasta el año 1290, año en que el rey Eduardo I decretó su expulsión del país. Durante el tiempo que permanecieron en Inglaterra los judíos se dedicaron a prestar dinero a la corona, sobre todo al rey Enrique III quien los protegía. No obstante, con la llegada al trono de Eduardo I, este cambió el sistema de financiación de la corona, optando por financiación italiana y los judíos cayeron en desgracia, fueron perseguidos y entre la población creció un sentimiento de antisemitismo. Según Corèdon y Williams (2004: 166) los judíos se convirtieron de este modo en chivos expiatorios de todos los males que sufría Inglaterra:

The Jews in Britain, most of whom arrived during the 11c from France, had long acted as bankers to the ruling and business classes (being permitted to lend money at interest whereas Christians were not). In Henry III's reign, the Jews had provided the king with much needed finance. However, in 1275, a statute was issued by Edward I forbidding this practice. He had developed a new system of banking using Italian cash advances by 1275 and no longer needed to protect the Jews. Strong anti-Semitic feeling continued, many Jews being made

3 Es necesario precisar que el estudio sobre los judíos no representa la visión actual que hay generalizada en España sobre los judíos, sino la que una vez existió.

4 De igual forma Ferro Rubial (2008) ha obtenido una radiografía del sistema articulado de valores de la sociedad gallega mediante el estudio de las comparaciones proverbiales y otras unidades fijas de la lengua gallega.

5 El imaginario es un concepto muy usado en Hispanoamérica que deriva del 'imaginario social', noción inventada y desarrollada por Castoriadis. Equivale a 'visión compartida', 'conciencia colectiva', 'imagen ingenua', etc. Aquí representa simplemente conjunto de ideas y creencias creadas y transmitidas culturalmente que gran parte o la mayoría de la población tiene sobre un determinado tema, grupo social, etc. 
scapegoats for England's difficulties. In 1287, Edward imprisoned and ransomed 3,000 of their number. The ransom was paid, but in 1290 an edict was issued expelling all Jews from England.

\subsection{Análisis ideológico de los judíos a través de los refranes}

Según los refranes españoles medievales que hacen alusión a los judíos se puede dibujar un retrato de los mismos que a su vez puede dividirse en diferentes aspectos (religiosos, sociales, económicos, físicos, actitudinales, etc.). Así, los judíos se caracterizan por':

\section{A. RELIGIÓN}

Desde el punto de vista religioso la comunidad judía se caracteriza por poseer unos rasgos peculiares diferentes a los de la comunidad cristiana que afectan a sus prácticas gastronómicas, sociales, fisiología, etc. Así:

A1.Siguen esperando inútilmente al mesías:

(1) Este puente espera el río como los judíos al Mesías ${ }^{7}$.

A2. No trabajan los sábados (el Sabbath):

(2) Porque el judío no medre, el merkado en sábado viene (cae el día de mercado en sábado)

(3) Achacoso como judío en sábado ${ }^{8}$.

(4) Ni da ni toma, komo judío en sábado.

(5) El judío, por medrar, el sábado a la puerta 9 .

A3. No comen cerdo:

(6) Jarro sin vino, olla sin tozino: mesa de judío i morisko.

(7) Ser una cosa como el tocino en casa del judío ${ }^{10}$.

A4. Celebran la pascua:

(8) Judíos en Pascuas, moros en bodas y cristianos en pleitos, gastan sus dineros.

\footnotetext{
${ }^{6}$ Se ha respetado la grafía de las distintas fuentes.

7 Según Sbarbi (1943), burla a cuenta del Manzanares, que espera inútilmente el agua como los judíos esperan inútilmente al Mesías. La burla de los ríos españoles por su falta de agua o por su suciedad es una manera indirecta de atacar a los habitantes de la ciudad o la zona por la que pasa el río.

8 Según Sbarbi (1943: 521) se dice los que se fingen enfermos con el intento de burlar el cumplimiento del deber, aludiendo a que si bien prohibía a los judíos su ley encender lumbre para hacer ni calentar la comida en el día del sábado, que equivale entre ellos a nuestro domingo, semejante precepto no regía con los achacosos o de salud quebrantada.

${ }^{9}$ Este refrán tomado del Seniloquium hace referencia al que no se da prisa y aprovecha el tiempo para sus negocios puede perder la oportunidad.

10 Según Sbarbi (1943), se aplica a aquello que, teniéndolo a nuestra disposición, no lo usamos ni hacemos caso de ello, aludiendo a la prohibición que por su ley tienen los judíos de comer carne de puerco.
} 


\section{A5. Están circuncidados:}

(9) Judío retajado (del que es circuncidado, según su ley).

\section{B.FÍSICO Y APARIENCIA}

Cada comunidad y cada raza se caracterizan por tener unas peculiaridades físicas y psíquicas. En el caso de los judíos, según los refranes de la época, las que más destacan son sobre todo el gran tamaño de la nariz y también por quejarse y gesticular en demasía. Así:

B1.Físicamente destacan por una gran nariz:

(10) No ai ke fiar de judío rromo, ni de hidalgo narigudo.

(11) Judío de larga nariz, paga la farda a Villacís.

B2. Gesticulan y son muy quejicosos:

(12) Hazer desgarro komo judío afrontado.

\section{CARÁCTER E INTELIGENCIA}

También a cada comunidad se le adjudican muchas características actitudinales que en ocasiones pueden estar basadas en la realidad y otras veces pueden ser solamente prejuicios que se tienen contra una determinada comunidad. Sea como fuere, lo cierto es que el imaginario que se ha creado de los judíos se basa en las siguientes características:

C1. Carecen de valor físico, viven atemorizados:

(13) Tener el judío en el kuerpo.

(14) Tener mucho judío en el kuerpo.

C2. Son buenos en los negocios:

(15) Ni judío nezio, ni liebre perezosa.

(16) El buen judio, de la paja hace oro ${ }^{11}$.

(17) Si el judío va llorando, el modéjar le ha engañado ${ }^{12}$.

C3. Son avaros. no gastan lo suficiente:

(18) El mezquino y el judío, en comiendo ha frío.

C4. Son vengativos:

(19) Abad, judío y madona, jamás perdona.

(20) Judío y dona y hombre con corona, jamás perdona.

\section{C5. Son traidores:}

(21) Juras de traidor, pasos son de liebre.

11 Según Sbarbi (1943: 521) expresa el carácter especulativo de la raza hebraica.

12 Según Correas (2000), "modéjar se llamaba en España, y ahora en Argel y África, al moro de Granada y Andalucía. Eran gente más ladina, y sagaz, y de más valor que los otros moros de allende y de aquende". 
C6. Son abusones, aprovechados, ventajistas, oportunistas:

(22) Al abad y al judío, daledes el guevo i pedirán el tochuelo ${ }^{13}$.

(23) Al judío, dalde un guevo i pediros á el tozuelo.

(24) Al judío dalde un palmo, i tomará kuatro.

C7. Son inteligentes y superan en astucia a los demás:

(25) Piensa don Zaga ke kon su hija tuerta me engaña; pues para el Dio, ermano, ke soi kontrecho de un lado.

(26) Judío para la merkaduria, i fraile para la ipokresía.

(27) $O$ es judío o sacristán ${ }^{14}$.

\section{ECONOMÍA}

Desde el punto de vista económico la comunidad medieval judía se ha caracterizado no solo en España sino en muchos otros países europeos por dedicarse principalmente al préstamo y la usura. No es de extrañar que existan muchos refranes que hacen referencia a esta práctica económica exclusiva durante muchos siglos de los judíos:

D1. Son explotadores:

(28) El kavallo del judío, harto de agua i bien corrido ${ }^{15}$.

D2. Son prestamistas, practican la usura:

(29) Ser un judío, o Tener conciencia de judío ${ }^{16}$.

(30) El kavallero ke no aiuda, el klérigo ke no da, el judío que no presta, es kosa molesta.

(31) El villano ke no mata puerko, i el judío ke no da a rrenuevo ${ }^{17}$, i el eskudero ke no gana sueldo, pónganse del duelo.

(32) Ni eskudero sin sueldo, ni judío sin rrenuevo.

D3. No realizan trabajos físicos:

(33) No es judío para el trabajo, ni el trabajo para el judío.

(34) No son los judíos para el trabajo.

13 Correas, p. 52: Tochuelo (por tozuelo "cerviz carnosa de un animal"). Otro ej.: "Al judío, dalde un güevo...".

14 Según Sbarbi (1943: 521), modo de indicar que una persona es taimada, o, como se dice vulgarmente, que es pájaro de cuenta.

15 El caballo del judío, harto de agua y bien corrido. Según Correas, p. 260 "Como el judío es odioso, si presta el caballo al hidalgo y cristiano viejo, en odio del amo dale mal de comer, córrele mucho y hártale de agua para que lleve barriga. Para el comento que puso el Comendador, había de decir: "El caballo del mezquino, harto de agua y bien corrido"; y se entiende: que el amo pobre no le puede dar mucho de comer, y el mozo hártale de agua y de correr; sucede que los mozos corren los caballos cuando los llevan a dar agua al pilón, o río".

16 Según Sbarbi (1943: 521), se suele aplicar al comerciante o prestamista usurero, aludiendo a la conciencia nada estrecha que en materia de intereses tiene aquel pueblo errante.

17 Préstamo y usura. 


\section{E.SUS RELACIONES CON LOS CRISTIANOS}

Como resultado del imaginario que se tenía de los judíos, los cristianos crearon una serie de refranes que de algún modo sentaban las bases para la convivencia de estos con los judíos. Así queda patente en los siguientes refranes:

E1. Están en todas partes:

(35) En la heredad, un guindo; y en la villa, un judío.

E2. No son fiables:

(36) Fraile ni judío, nunka buen amigo.

(37) Kien toma judío por konpañero, del kabrón le haze kamero.

(38) Klérigo, fraile o judío, no le tengas por amigo.

(39) Al judío y al puerco no lo metas en tu huerto.

E3. Son perseguidos por la inquisición, se desea su marcha, etc.:

(40) Dámelo judío y dártelo he quemado ${ }^{18}$.

(41) Judio de larga nariz, paga la farda a Villasís ${ }^{19}$.

(42) Ea, judíos, a enfardelar, que mandan los reyes que paséis la $\operatorname{mar}^{20}$.

E4. Tienen suerte (inmerecida):

(43) No tuviera más ventura un judío.

(44) Venturoso komo judío/ Más venturoso ke un judío.

(45) Dicha de judío.

E5. Son personas inferiores:

(46) Para mujer, judío ni abad, no debe hombre mostrar rostro ni esfuerzo ${ }^{21}$.

\section{CONCLUSIÓN}

A través de la clasificación y exposición de los refranes sobre judíos existentes en el español medieval se ha intentado ofrecer un retrato robot de esta comunidad en la España medieval. No obstante, hay que indicar que muchos de los tópicos negativos sobre judíos que aparecen en español

18 Según Sbarbi (1943: 521) alude al peligro que corrían en tiempos de la Inquisición, de caer en sus manos, los que no eran considerados como buenos cristianos.

19 Según Sbarbi (1943: 521), refrán muy corriente en Sevilla a fines del siglo XV, con motivo de la persecución suscitada contra los hebreos por parte del vecindario, y muy especialmente por el recaudador de las rentas de los reyes y de la Inquisición, un tal Villasís, quien no les daba treguas para el pago de las contribuciones o impuestos a aquellos infelices.

20 Según Sbarbi (1943: 521), expresión que dirigía el pueblo español a los judíos cuando se decretó su proscripción por los Reyes Católicos en el año de 1492, y que pasó después a usarse proverbialmente con el objeto de significar a alguien que se ausente o se quite de la presencia de uno cuanto antes.

21 Según Sbarbi (1943), esto se debe interpretar en que "se conceptúan de tan exiguo valor, que no vale la pena molestarse lo más mínimo por ellos" 
no son solo privativos de esta lengua sino que conforman un imaginario compartido lleno de prejuicios al respecto de este grupo social. Este imaginario se ha visto reforzado por la realidad histórica de la difícil convivencia de los judíos a lo largo de los siglos en muchos países europeos. Piénsese por ejemplo en la expresión inglesa worth a Jew's eye que equivale a algo muy valioso y que procede de la costumbre medieval de torturar a los judíos para sacarles el dinero. Según Brewer (1870) esta expresión se remonta a los tiempos del rey Juan (1166-1216) quién requirió 10.000 marcos a un rico judío de Bristol. Este se negó a entregarle el dinero y fue apresado. La tortura que sufrió fue la extracción de un diente por cada día que el dinero se demorase en llegar a palacio. Al séptimo día el judío se rindió y el rey afirmó que "A Jew's eye may be a quick ransom, but Jew's teeth give the richer harvest" ${ }^{\prime 2}$.

En muchas otras lenguas europeas existen palabras y expresiones que demuestran la difícil convivencia que los judíos han tenido a lo largo de los siglos en los distintos países de Europa. A esta difícil convivencia hay que añadir los prejuicios que se han vertido sobre la comunidad judía sobre todo durante el nazismo en los proverbios alemanes contra los judíos ${ }^{23}$. Los prejucios tienen una validez en la lengua que persiste en el tiempo aun cuando el referente al que hacían referencia ya no esté vigente. En el caso concreto de los judíos esto ha sido observado por Jerzy Slawomirski quien en su trabajo El antisemitismo como hecho del lenguaje: algunos ejemplos en la lengua polaca (1993) ha demostrado que en polaco existen una gran cantidad de expresiones antisemitas aún cuando en la actualidad ya no existe una población judía en Polonia. Algunas de estas expresiones son (1993:131):

(1) Kochajmy się jak bracia, liczmy się jak żydzi (Lit. amémonos como hermanos, hagamos las cuentas como los judíos).

(2) Ale z ciebie żyd! (Lit. ¡Qué judío eres! ${ }^{24}$ ).

(3) Rozpuszczony jak żydowski bachor (Lit. maleducado como un judezno).

(4) Co się tak kiwasz jak żyd przy szabasie [o nad Talmudem] (Lit. Por qué te balanceas como un judío sobre la cena de Sabbat? [o sobre el Talmud]) ${ }^{25}$.

(5) Skoncz te żydowskie pienia! (Lit. deja de una vez esos cánticos judíos!) ${ }^{26}$.

(6) żydowski filozof! (Lit. ¡Vaya un filósofo judío! ${ }^{27}$ ).

\footnotetext{
${ }^{22}$ Esta expresión también aparece en el Mercader de Venecia (ii:5) cuando Lancelot dice a Jessica: "There will come a Christian by/ Will be worth a Jewess' eye".

${ }^{23}$ Véase al respecto el trabajo de Wolfgang Mieder (1982): "Proverbs in Nazi Germany. The Promulgation of Anti-Semitism and Stereotypes through Folklore". En Journal of American Folklore. Volume: 95 . Issue: 378.

${ }^{24} \mathrm{Se} u$ tiliza para referirse a alguien muy minucioso en las cuentas

${ }^{25}$ Se dice a un niño que está intranquilo en la mesa

${ }^{26}$ Se dice a un niño que desafina o que simplemente canta en voz alta.

${ }^{27}$ Se dice a un niño sabiondo.
} 
(7) żydowski rejwach (podnieść) (Lit. Un jaleo judío (armar) ${ }^{28}$ ).

(8) Obetnij te żydowskie pejsy! (Lit. ¡Córtate esos mechones judíos!) ${ }^{29}$

(9) Wyplamiony jak żydowski chałat (Lit. Manchado como una túnica judía) ${ }^{30}$.

(10) Zdejm czapk, nie jesteś żydem! (Lit. ¡Quítate el gorro, que no eres un judío!) $)^{31}$.

(11) Zrobić żyda (Lit. Hacer un judío) ${ }^{32}$.

Finalmente, Slawomirski crea también su retrato robot de la comunidad judía basándose en el análisis de las expresiones arriba mencionadas. Así, concluye que un judío (żyd) se podría definir como una persona ávida, avara, maleducada, ruidosa y pesada, presumida, incontinente, negligente y sucia ${ }^{33}$.

\section{REFERENCIAS BIBLIOGRÁFICAS}

BREWER, Ebenezer. Dictionary of Phrase and Fable. New York: Harper \& Row, 1870.

CARRASCO, Rafael e Irene ANDRÉS SUÁREZ. "Textos sobre judíos moros y conversos". En: Andrés Suárez, Irene (ed.), Las dos grandes minorías étnico-religiosas en la literatura española del Siglo de Oro: los judeoconversos y los moriscos. Paris: Les Belles lettres, 1995, pp. 149-154.

CEJAdOR Y FraucA, Julio, Diccionario fraseológico del siglo de oro (Fraseología o estilística castellana). Barcelona: Ediciones del Serbal, 2008.

COMBET, L. "Recherches sur le 'Refranero' Castillan”. Paris: Bibliothèque de la Faculté des Lettres de Lyon. Fascicule XXIX. "Les Belles Lettres", 1971, pp. 477- 486.

CORĖdON, Christopher y Ann WILLIAMS. A dictionary of medieval terms and phrases. Cambridge: D.S. Brewer, 2004.

CORREAS, Gonzalo, Vocabulario de refranes y frases proverbiales. Edición de Louis Combet. Madrid: Nueva Biblioteca de Erudición y Crítica. Editorial Castalia, [1627] 2000.

\footnotetext{
${ }^{28}$ Se dice de alguien que reacciona gritando y haciendo aspavientos exagerados.

${ }^{29}$ Dirigido a un chico que tiene el pelo descuidado.

${ }^{30}$ Referido a un vestido sucio.

${ }^{31}$ Dirigido a alguien que se olvida de descubrirse al entrar en una casa.

32 Hacer un borrón.

${ }^{33}$ En su estudio sobre las expresiones polacas actuales sobre los judíos Slawomirski puntualiza que dichas expresiones no suponen la exaltación del antisemitismo polaco sino una mera transmisión de expresiones y paremias que han hecho que hoy en día se siga teniendo ese imaginario de los judíos.
} 
Ferro Ruibal, Xesú. "La fraseología, espejo de la historia de un pueblo". En: Luque Durán, J.D y Pamies Bertrán, A. (eds.): La creatividad en el lenguaje. Granada: Método, 2005, pp. 257-282.

"A comparación fraseolóxica galega como radiografía lingüística". En: Álvarez de la Granja, M. (coord.). Lenguaje figurado y motivación: una perspectiva desde la fraseología. Frankfurt am Main: Peter Lang, 2008, pp. 129-190.

GaRcíA DE CASTRO, Diego, Refranes que dicen los viejos. "Seniloquium". Traducción y edición crítica de Fernando Cantalapiedra Erostarbe y Juan Moreno Uclés. Valencia: Publicacions de la Universitat, 2006.

LUQUE DURÁN, Juan de Dios. "Las colocaciones de cuantificación por comparación: tradición e innovación en las comparaciones proverbiales". En: Luque Durán, J.D y y Pamies Bertrán, A. (eds.): La creatividad en el lenguaje. Granada: Método, 2005, pp. 409-456.

PAMIES BerTRÁN, Antonio. "Comparación esterotipada y colocación en español y francés". En: Luque Durán, J.D. y Pamies Bertrán, A. (eds.): La creatividad en el lenguaje. Granada: Método, 2005, pp. 469-484.

SBARBI Y OSUNA, José María. Diccionario de refranes, adagios, proverbios, modismos, locuciones y frases proverbiales de la lengua española. Madrid: Hernando, 1922.

, El gran diccionario de refranes de la lengua española. Buenos Aires: Joaquín Gil, 1943.

SLAWOMIRSKI, Jerzy, "El antisemitismo como hecho del lenguaje: Algunos ejemplos en la lengua polaca". En: Sendebar 4, 1993, pp. 129-132. 